\title{
SOLUBLE CELL ADHESION MOLECULES S-VCAM-1 AND S-ICAM-1 IN SUBJECTS WITH FAMILIAL COMBINED HYPERLIPIDEMIA
}

\author{
David Karásek $^{\text {a*}, \text { Helena Vaverkováa }}{ }^{\mathrm{a}}$ Milan Halenka ${ }^{\mathrm{a}}$, Marie Budíkováb, Dalibor Novotnýc
}

\author{
a $3^{\text {rd }}$ Department of Internal Medicine, Teaching Hospital, Olomouc, Czech Republic \\ ${ }^{b}$ Department of Nuclear Medicine, Teaching Hospital, Olomouc, Czech Republic \\ c Department of Clinical Biochemistry, Teaching Hospital, Olomouc, Czech Republic \\ e-mail:david.karasek@fnol.cz
}

Received: April 15, 2005; Accepted: May 24, 2005

Key words: Intercellular adhesion molecule-1/Vascular cell adhesion molecule-1/Familial combined hyperlipidemia/ intima-media thickness/Atherosclerosis

Familial combined hyperlipidemia $(\mathrm{FCH})$ is the most common familial hyperlipidemia with a high risk for early atherosclerosis. The aim of this study was to compare levels of soluble intercellular cell adhesion molecule 1 (s-ICAM-1) and soluble vascular cell adhesion molecule 1 (s-VCAM-1) in asymptomatic members of FCH families with healthy controls and to determine the relation between s-ICAM-1, s-VCAM-1 and risk factors accompanying FCH. We also investigated the association between adhesion molecules and the intima-media thickness (IMT) of the common carotid artery, a recognized morphological marker of early atherosclerosis. 82 members of 29 FCH families were divided into the 2 groups: HL (probands and hyperlipidemic first-degree relatives, $n=47$ ) and NL (normolipidemic first-degree relatives, $n=35)$. The control groups - HL-C $(n=20)$ and NL-C $(n=20)$ - consisted of sex- and age-matched healthy individuals. Hyperlipidemic members had significantly higher concentration of s-ICAM-1 (633.7 $\pm 169.6 \mathrm{ng} / \mathrm{ml} \mathrm{versus}$ $546.2 \pm 155.9 \mathrm{ng} / \mathrm{ml}, \mathrm{p}<0.05)$. The elevation of s-VCAM-1 was not significant $(880.8 \pm 202.9 \mathrm{ng} / \mathrm{ml}$ versus $826.5 \pm 174.6$ $\mathrm{ng} / \mathrm{ml}$, N.S.). Levels of s-ICAM-1 and of s-VCAM-1 in normolipidemic relatives were not significantly different from the control group $(530.8 \pm 113.9 \mathrm{ng} / \mathrm{ml}$ versus $530.0 \pm 101.0 \mathrm{ng} / \mathrm{ml}$ and $860.2 \pm 265.7 \mathrm{ng} / \mathrm{ml}$ versus $822.1 \pm 197.0 \mathrm{ng} / \mathrm{ml}$ respectively). There was a significant correlation between s-ICAM-1 and apoB $(r=0.42 ; p<0.01)$ in hyperlipidemic subjects and between s-ICAM-1 and proinsulin $(\mathrm{r}=0.54 ; \mathrm{p}<0.01)$ in normolipidemic subjects. S-ICAM-1 correlated with IMT $(r=0.32 ; p<0.05)$ in all members of FCH families. The increase of s-ICAM-1 in asymptomatic hyperlipidemic members of FCH families reflects their high cardiovascular risk. The positive association between s-ICAM-1 and IMT could indicate s- ICAM-1 as a potential predictor of atherosclerosis manifestation.

Abbreviations: apoB, apolipoprotein B; BMI, body mass index; CCA, common carotid artery; CHD, coronary heart disease; DBP, diastolic blood pressure; $\mathrm{FCH}$, familial combined hyperlipidemia; HDL, high density lipoprotein; HDL-C, HDL cholesterol; HL, hyperlipidemic members of FCH families; HOMA, homeostasis model assessment; hs-CRP, high sensitivity $\mathrm{C}$ reactive protein; IMT, intima-media thickness; IRMA, immunoradiometric assay; LDL, low density lipoprotein; LDL-C, LDL-cholesterol; NL, normolipidemic members of FCH families; non-HDL-C, non-HDL cholesterol; RIA, radioimmune assay; SBP, systolic blood pressure; s-ICAM-1, soluble intercellular cell adhesion molecule 1; s-VCAM-1, soluble vascular cell adhesion molecule 1; TC, total cholesterol; TG, triglycerides; VLDL, very low density lipoprotein.

\section{INTRODUCTION}

Familial combined hyperlipidemia $(\mathrm{FCH})$ is the most common genetic hyperlipidemia, affecting $1.0 \%$ to $2.0 \%$ of the population, and it has a high risk of early atherosclerosis manifestation ( $10 \%$ to $20 \%$ of survivors of premature myocardial infarction exhibit FCH) (ref., ${ }^{1,2}$ ). FCH is characterized by increased levels of apolipoprotein B (apoB) containing lipoproteins - very low density lipoproteins (VLDL) and low density lipoproteins (LDL), particularly small, dense LDL ( ref. $^{3-5}$ ). FCH is frequently associated with a decrease in high density lipoprotein cholesterol (HDL-C) concentration, altered metabolism of fatty acids, prolonged postprandial lipaemia and impaired activity of lipoprotein lipase. In addition, $\mathrm{FCH}$ is associated with arterial hypertension and insulin resistance ${ }^{6,7}$. The lipids and lipoprotein levels in FCH are - in comparison with familial hypercholesterolemia - relatively moderately elevated and do not fully explain the highly increased risk of cardiovascular disease. 
Intercellular cell adhesion molecule 1 (ICAM-1) and vascular cell adhesion molecule 1 (VCAM-1) are two members of the immunoglobulin gene superfamily that play important, but different roles in the adhesion of leukocytes to the vascular endothelium. VCAM-1, which is the endothelial ligand for very late antigen 4 , has been postulated to play the more critical role in monocyte adherence to endothelial cells under flow conditions. ICAM-1 ligands include CD11a/CD18 (lymphocyte function associated antigen-1) and CD11b/CD18 (macrophage antigen-1), which are present on monocytes, lymphocytes, and neutrophils. Increased expression of ICAM-1 and VCAM-1 is observed in atherosclerotic lesions, and mice deficient in either ICAM-1 or VCAM-1 have reduced response to experimental atherosclerotic stimuli. Cytokine activation dramatically up-regulates their expression on the cell surface where they support the interaction of leukocytes and endothelial cells ${ }^{8-10}$. Recently, in addition to being expressed on the cell surface, soluble forms of adhesion molecules have been detected in circulating blood and have been shown to retain their functional ability. A number of clinical investigators have measured levels of soluble ICAM-1 (s-ICAM-1) and/or VCAM-1 (s-VCAM-1) as potential biomarkers for endothelial dysfunction and early atherosclerosis.

The intima-media thickness (IMT) of the common carotid artery is a recognized morphological marker of early atherosclerosis. IMT reflects integrally the effect of individual risk factors of atherosclerosis and some intervention measures performed to eliminate the effect of these risk factors ${ }^{11-13}$. Moreover, IMT represents the ultrasound parameter with a good predictive value on the generalized status of atherosclerosis of coronary ${ }^{14-16}$, cerebral ${ }^{17,18}$ and lower extremity arteries ${ }^{19,20}$.

The aim of this study was to investigate whether asymptomatic members of $\mathrm{FCH}$ families (without clinical manifestation of atherosclerosis) have higher plasma levels of s-ICAM-1 and/or s-VCAM-1 than controls. Furthermore, we studied whether parameters of lipid metabolism and insulin resistance are related to s-ICAM-1 and/or s-VCAM-1 levels. We also investigated the correlation between the above mentioned adhesion molecules and IMT of the common carotid artery.

\section{MATERIAL AND METHODS}

The study was carried out with 82 members of $29 \mathrm{FCH}$ families, who had been examined in the Lipid Center of the $3^{\text {rd }}$ Department of Internal Medicine, University Hospital Olomouc. A family with $\mathrm{FCH}$ was defined in the study under the following criteria. The proband exhibiting a combined hyperlipidemia should have both plasma total cholesterol (TC) and triglycerides (TG) concentrations above the $90^{\text {th }}$ percentile, adjusted for age and gender, as obtained from the MONICA study, based on data from the Czech population (Table 1) (ref. ${ }^{21}$ ). At least one firstdegree relative of the proband should have plasma TC and/or TG above $90^{\text {th }}$ percentile, adjusted for age and
Table 1. Values of $90^{\text {th }}$ percentiles of Czech population for total cholesterol and triglycerides in men and women in individual age categories (Czech post-MONICA study, kindly provided by doc. MUDr. R. Cifkova, CSc., IKEM, Prague).

\begin{tabular}{|c|c|c|c|c|}
\hline $\begin{array}{c}\text { Age } \\
\text { category }\end{array}$ & \multicolumn{2}{|c|}{ Men } & \multicolumn{2}{c|}{ Women } \\
\hline (years) & $\begin{array}{c}\mathrm{TC} \\
(\mathrm{mmol} / 1)\end{array}$ & $\begin{array}{c}\mathrm{TG} \\
(\mathrm{mmol} / \mathrm{l})\end{array}$ & $\begin{array}{c}\mathrm{TC} \\
(\mathrm{mmol} / \mathrm{l})\end{array}$ & $\begin{array}{c}\mathrm{TG} \\
(\mathrm{mmol} / \mathrm{l})\end{array}$ \\
\hline$<35$ & 6.75 & 3.11 & 5.97 & 1.65 \\
\hline $35-44$ & 7.28 & 3.64 & 6.64 & 2.05 \\
\hline $45-55$ & 7.32 & 3.83 & 7.31 & 2.75 \\
\hline$>55$ & 7.43 & 3.64 & 8.04 & 3.13 \\
\hline
\end{tabular}

$\mathrm{TC}=$ total cholesterol, $\mathrm{TG}=$ triglycerides

gender, or a level of apoB $\geq 1.25 \mathrm{~g} / 1$ (ref. $\left.^{22,23}\right)$. At the same time, secondary or another primary hyperlipoproteinemia was excluded in those subjects. All subjects were tested for an underlying cause of secondary hyperlipidemia: diabetes mellitus, hypothyroidism, hepatic or renal impairment and nephrotic syndrome. None of the probands in these families were homozygous for the apo-E2 allele and none of them or their first-degree relatives had tendon xanthomas. Other exclusion criteria were as follows: history of clinically manifest atherosclerosis (coronary artery disease, heart failure, cerebrovascular ischemic disease, peripheral vascular disease), smoking, hypolipidemic therapy in the previous 8 weeks, hormone therapy with estrogens and clinical presence of acute infectious disease or trauma.

Members of FCH families were divided into two groups: HL (hyperlipidemic members of FCH families, i.e. probands and their hyperlipidemic first-degree relatives, having plasma TC and/or TG level $>$ the $90^{\text {th }}$ percentile adjusted for age and gender, or the level of apoB $\geq 1.25 \mathrm{~g} / 1$ ) and NL (normolipidemic first degree relatives, who did not meet the above - mentioned criteria.). The control groups (HL-C and NL-C) - were sex- and agematched to groups HL and NL. Control groups consisted of healthy individuals with a negative family history of hyperlipidemia and early manifestation of atherosclerosis. The Ethics Committee of the Medical Faculty and University Hospital Olomouc approved the design of the study and informed consent was obtained from all participants.

All subjects filled out a questionnaire on their previous medical history, especially cardiovascular status, medication, and smoking habits. Body mass index (BMI), waist circumference, systolic and diastolic blood pressure (SBP, DBP) were determined in all subjects. Venous blood samples were drawn in the morning after a $12 \mathrm{~h}$ fast. Total cholesterol, triglycerides and HDL-C were determined enzymatically on a Hitachi 917 analyzer (Roche, Basel, Switzerland). Determination of HDL-C was made by a direct method without precipitation of apoB containing 
lipoproteins. LDL-C levels were calculated according to the Friedewald formula (for TG $<4.5 \mathrm{mmol} / \mathrm{l}$ ). Concentration of apoB was determined immunoturbidimetrically using specific antibodies - Tina-Quant apoB kit (Roche, Basel, Switzerland). C-reactive protein (hs-CRP) was assessed by means of an ultra sensitive immunoturbidimetric method using the kit Tina-Quant CRP (Roche, Basel, Switzerland). Glycemia was determined using the enzyme based kit Glucose GOD-PAP. Insulin was determined using the commercially available kits - Insuline (Immunotech, Marseille, France) using specific antibodies by IRMA method. The result obtained was then used for calculation of the parameter of insulin resistance HOMA (homeostasis model assessment, described by Matthews et al.: fasting glycemia $\times$ fasting insulin / 22.5) $\left(\right.$ ref. $\left.^{24}\right)$. C-peptide and proinsulin were determined using the commercially available kits - C-peptide (Immunotech, Marseille, France) and Proinsulin (DRG Instruments GmbH, Marburg, Germany) using specific antibodies by IRMA method (for C-peptide) and RIA method (for proinsulin). Serum levels of the soluble adhesion molecules s-ICAM-1 and s-VCAM-1 were measured by immunoenzymatic assay using commercially available standard kits - s-ICAM-1 and s-VCAM-1 (Immunotech, Marseille, France). Ultrasound scanning of IMT was performed with a $10 \mathrm{MHz}$ linear array transducer (Hewlett-Packard, Image Point, M2410A, 1997). All measurements were performed with the subjects in a supine position. The head was tilted to the one side at an angle of $45^{\circ}$. The longitudinal B-mode image of the common carotid artery (CCA) was displayed just before the widening of the bulb. When an optimal longitudinal image of the far wall of the CCA in the region of $1 \mathrm{~cm}$ proximally from the bulb was obtained, it was frozen on the $\mathrm{R}$ wave according to a simultaneous ECG and videotaped (Panasonic VCR, AG-MD 830, S-VHS videocassette). Three video records were made on both CCA. IMT measurements were processed off-line using the software Image-Pro Plus (Version 4.0, Media-Cybernetics, Silver Spring, USA). The region under evaluation was the CCA wall 1-2 cm distant proximally from the mentioned border. The average of all mean IMT of three frozen images of both sides was chosen as the outcome variable. Subjects with an atherosclerotic plaque in the evaluated region were not included in the study. IMT was registered and evaluated independently by two physicians and the inter- and intra-individual variability of ultrasound measurements was evaluated in 22 healthy subjects (12 women, 10 men, mean age of $35.2 \pm 7.8$ years), who were examined repeatedly at an interval of one month. Mean differences were for IMT CCA sinistra $0.030 \pm 0.027$ $\mathrm{mm}$, IMT CCA dextra $0.030 \pm 0.021 \mathrm{~mm}$ and mean IMT $0.032 \pm 0.021 \mathrm{~mm}$. Variation coefficients were $2.18 \%$ for IMT CCA sinistra, $2.05 \%$ for IMT CCA dextra and $1.72 \%$ for mean IMT. The measurement of IMT was made without knowledge of laboratory results.

All values given in the present paper are expressed as means $\pm \mathrm{SD}$. Comparison of individual groups ( $\mathrm{FCH}$ subjects respectively normolipidemic subjects and controls) was made using a Mann-Whitney U test, because this test assumes eventual non normal data distribution. It is based on simple ranking of data. For statistical evaluation of the dependence of s-ICAM-1 and of s-VCAM-1 on risk factors for atherosclerosis and their relation to IMT we used a univariate correlation analysis. A Kolmogorov-Smirnov test was used to test for normal distribution and a Pearson correlation test was subsequently used in the case of normal distribution of constants. In the case of abnormal distribution of constants (TG, proinsulin, insulin, C-peptide, HOMA, SBP, DBP) we used Spearman correlation test. Statistical analysis was using SPSS for Windows version 12.0 (Chicago, Illinois, USA). Probability values of $\mathrm{p}<0.05$ were considered as statistically significant.

\section{RESULTS}

\section{Basic characteristics}

Table 2 shows the anthropometric and biochemical characteristics and IMT in subjects with FCH (HL) and their normolipidemic relatives (NL) compared to controls (HL-C and NL-C respectively). In comparison to sex- and age- matched controls, hyperlipidemic subjects had significantly higher DBP, BMI and exhibited insulin resistance - significantly elevated levels of C-peptide and proinsulin compared to controls. They also had higher hs-CRP. By definition the FCH subjects had higher plasma TC and TG concentrations compared to controls and normolipidemic relatives. In addition, they had a more atherogenic lipid and lipoprotein profile as reflected by increased LDL-C and apoB concentrations. Hyperlipidemic subjects had also significantly higher IMT compared to healthy controls. Normolipidemic relatives had significantly higher diastolic blood pressure, TG and proinsulin concentrations compared to their sex- and age- matched controls. There was no difference in IMT and other measured anthropometric and biochemical parameters.

\section{Levels of s-ICAM-1 and $s$-VCAM-1}

The first aim of this study was to investigate whether subjects with FCH or their normolipidemic relatives had higher plasma levels of soluble cell adhesion molecules (s-VCAM-1 and s-ICAM-1) than controls (graph 1, 2). In comparison to healthy sex- and age- matched controls, the hyperlipidemic individuals had significantly higher levels of s-ICAM-1 $(633.7 \pm 169.6 \mathrm{ng} / \mathrm{ml}$ versus $546.2 \pm 155.9 \mathrm{ng} / \mathrm{ml}, \mathrm{p}<0.05)$. No significant difference was found in the levels of s-VCAM-1 $(880.8 \pm 202.9 \mathrm{ng} / \mathrm{ml}$ versus $826.5 \pm 174.6 \mathrm{ng} / \mathrm{ml}$ ) in these groups. The levels of s-VCAM-1, respectively of s-ICAM-1 in normolipidemic relatives were not significantly different from sex- and agematched controls $(860.2 \pm 265.7$ versus $822.1 \pm 197.0$, respectively $530.8 \pm 113.9$ versus $530.0 \pm 101.0)$.

\section{Relation to metabolic parameters, anthropometric parameters, and IMT}

In hyperlipidemic subjects a significant correlation was found between s-ICAM-1 and apoB $(r=0.42, p<0.01)$. In the group of normolipidemic subjects a significant correla- 
Table 2. Basic characteristics in individual groups

\begin{tabular}{|c|c|c|c|c|}
\hline & $\mathrm{HL}$ & HL-C & NL & NL-C \\
\hline women/men & $20 / 27$ & $8 / 12$ & $24 / 11$ & $14 / 6$ \\
\hline age (years) & $44.7 \pm 1.5$ & $44.2 \pm 13.5$ & $31.5 \pm 11.0$ & $31.8 \pm 7.6$ \\
\hline $\mathrm{TC}(\mathrm{mmol} / \mathrm{l})$ & $6.96 \pm 1.16^{* * *}$ & $4.88 \pm 0.92$ & $4.88 \pm 0.72$ & $4.82 \pm 0.58$ \\
\hline $\mathrm{TG}(\mathrm{mmol} / \mathrm{l})$ & $3.01 \pm 2.20 * * *$ & $1.15 \pm 0.54$ & $1.25 \pm 0.43^{* *}$ & $0.92 \pm 0.34$ \\
\hline HDL-C $(\mathrm{mmol} / \mathrm{l})$ & $1.43 \pm 0.41$ & $1.49 \pm 0.32$ & $1.53 \pm 0.42$ & $1.61 \pm 0.41$ \\
\hline LDL-C (mmol/l) & $4.25 \pm 1.27 * * *$ & $2.87 \pm 0.76$ & $2.76 \pm 0.62$ & $2.75 \pm 0.45$ \\
\hline non-HDL-C (mmol/1) & $5.53 \pm 1.03 * * *$ & $3.4 \pm 0.88$ & $3.35 \pm 0.71$ & $3.21 \pm 0.49$ \\
\hline apoB (g/l) & $1.39 \pm 0.23^{* * *}$ & $0.92 \pm 0.21$ & $0.93 \pm 0.24$ & $0.90 \pm 0.11$ \\
\hline SBP (mm Hg) & $127 \pm 12$ & $123 \pm 12$ & $119 \pm 15$ & $120 \pm 9$ \\
\hline $\mathrm{DBP}(\mathrm{mm} \mathrm{Hg})$ & $82 \pm 6 * * *$ & $75 \pm 9$ & $77 \pm 8^{*}$ & $71 \pm 9$ \\
\hline BMI $\left(\mathrm{kg} / \mathrm{m}^{2}\right)$ & $26.5 \pm 3.0^{*}$ & $24.7 \pm 2.4$ & $22.4 \pm 3.0$ & $23.0 \pm 2.6$ \\
\hline waist circumference $(\mathrm{cm})$ & $88 \pm 11$ & $84 \pm 11$ & $75 \pm 10$ & $76 \pm 8$ \\
\hline fasting glycemia $(\mathrm{mmol} / \mathrm{l})$ & $5.16 \pm 0.78 *$ & $4.76 \pm 0.49$ & $4.98 \pm 0.92$ & $4.62 \pm 0.32$ \\
\hline C-peptide (mg/l) & $2.68 \pm 1.69^{*}$ & $1.99 \pm 1.20$ & $1.95 \pm 0.69$ & $1.66 \pm 0.66$ \\
\hline proinsulin (mIU/l) & $17.57 \pm 13.02 *$ & $11.25 \pm 8.41$ & $11.27 \pm 3.82 *$ & $8.26 \pm 1.57$ \\
\hline insulin $(\mathrm{mIU} / \mathrm{l})$ & $9.52 \pm 6.25$ & $7.38 \pm 4.33$ & $7.13 \pm 2.48$ & $6.97 \pm 2.69$ \\
\hline $\operatorname{HOMA}\left(\mathrm{mIU}{ }^{*} \mathrm{mmol} / \mathrm{l}^{2}\right)$ & $2.29 \pm 1.80$ & $1.62 \pm 1.19$ & $1.61 \pm 0.73$ & $1.45 \pm 0.61$ \\
\hline hs-CRP (mg/l) & $2.13 \pm 1.71^{*}$ & $1.10 \pm 1.23$ & $2.17 \pm 2.50$ & $1.50 \pm 1.83$ \\
\hline IMT (mm) & $0.68 \pm 0.11 * * *$ & $0.60 \pm 0.07$ & $0.55 \pm 0.05$ & $0.55 \pm 0.04$ \\
\hline
\end{tabular}

$\mathrm{TC}=$ total cholesterol, $\mathrm{TG}=$ triglycerides, HDL-C $=$ HDL cholesterol, LDL-C $=$ LDL-cholesterol, non-HDL-C $=$ nonHDL cholesterol (TC - HDL-C), apoB = apolipoprotein B, SBP = systolic blood pressure, DBP = diastolic blood pressure, $\mathrm{BMI}=$ body mass index, HOMA $=$ homeostasis model assessment [fasting glycemia $\times$ fasting insulin $/ 22.5$ ], hs-CRP = high sensitivity $\mathrm{C}$ reactive protein, IMT = intima-media thickness of the common carotid artery

$\mathrm{HL}=$ hyperlipidemic members of FCH families, $\mathrm{HL}-\mathrm{C}=$ control group of $\mathrm{HL}$

$\mathrm{NL}=$ normolipidemic members of FCH families, NL-C = control group of NL

$* \sim \mathrm{p}<0.05, * * \sim \mathrm{p}<0.01, * * * \sim \mathrm{p}<0.001$...statistical significance level (Mann Whitney $-\mathrm{U}$ test)

tion was found between s-ICAM-1 and proinsulin $(r=0.54$, $\mathrm{p}<0.01)$. There was no significant correlation between s-VCAM-1 and measured anthropometric and biochemical parameters either in these groups. IMT of all members of FCH families (NL+HL) significantly correlated with s-ICAM-1 (graph 3), but not with s-VCAM-1.

\section{DISCUSSION}

FCH is associated with early atherosclerosis, despite a relatively late manifestation of hyperlipidemia. The lipids and lipoprotein levels in FCH are relatively moderately elevated and do not fully explain the total increased risk of cardiovascular disease. Thus surrogate markers of vascular damage are investigated to better identify subject with higher cardiovascular risk ${ }^{25}$. Soluble adhesion molecules - s-ICAM-1 and s-VCAM-1 - are accepted as potential biomarkers for endothelial dysfunction and atherosclerosis. The primary aim of this study was to investigate whether asymptomatic members of $\mathrm{FCH}$ families have higher plasma levels of s-ICAM-1 and/or s-VCAM-1 than controls. This study shows that asymptomatic subjects with FCH have increased levels of s-ICAM-1 - in contrast to levels of s-VCAM-1 - compared to sex- and age- matched controls. Their normolipidemic relatives exhibit no significant differences either of s-VCAM- 1 or of s-ICAM-1 concentrations.

Four large prospective studies of healthy individuals have shown a relationship between s-ICAM-1 and inci- 
s-ICAM-1 (ng/ml)

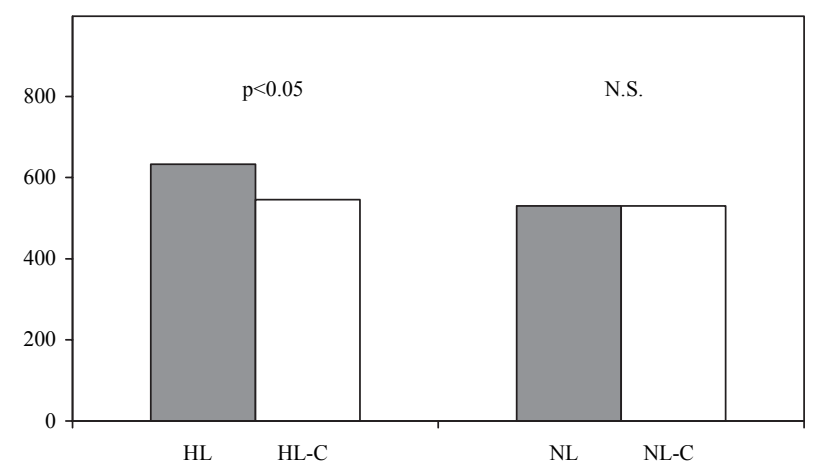

Graph 1. Levels of s-ICAM-1 in individual groups

s-ICAM-1 = soluble intercellular adhesion molecule - 1

$\mathrm{HL}=$ hyperlipidemic members of $\mathrm{FCH}$ families,

HL-C = control group of HL

$\mathrm{NL}=$ normolipidemic members of $\mathrm{FCH}$ families,

NL-C = control group of NL

$\mathrm{p} \sim$ statistical significance level (Mann Whitney - U test),

N.S. = non significant
s-VCAM-1 (ng/ml)

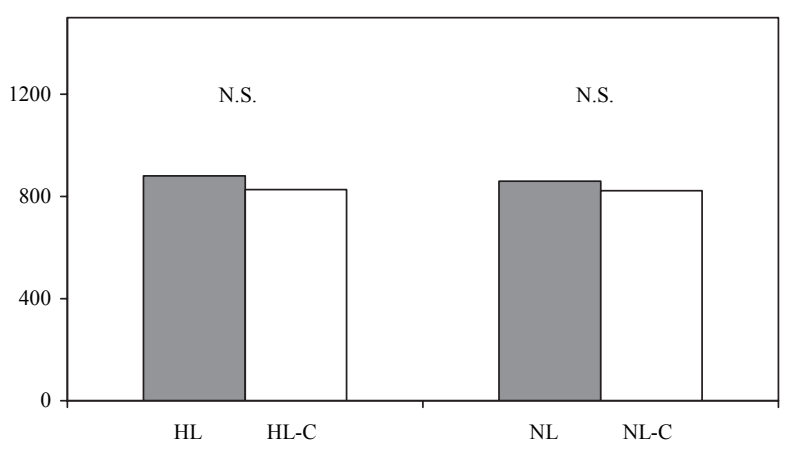

Graph 2. Levels of s-VCAM-1 in individual groups

s-VCAM-1 = soluble vascular cell adhesion molecule -1

$\mathrm{HL}=$ hyperlipidemic members of $\mathrm{FCH}$ families,

HL-C = control group of HL

$\mathrm{NL}=$ normolipidemic members of $\mathrm{FCH}$ families,

NL-C = control group of NL

$\mathrm{p} \sim$ statistical significance level (Mann Whitney - U test),

N.S. = non significant

\section{IMT (mm)}

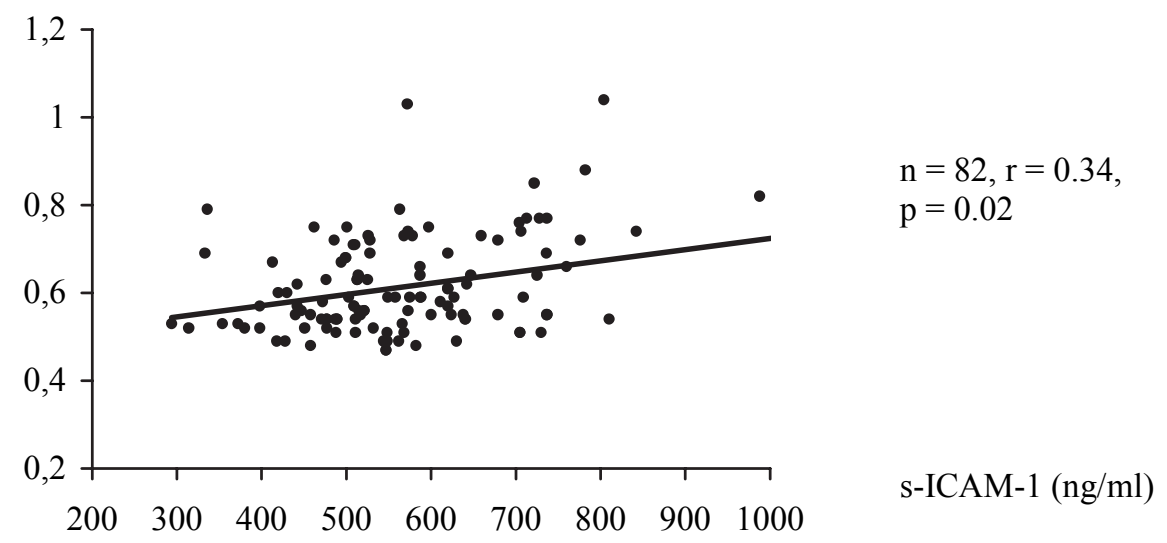

Graph 3. Correlation between IMT and ICAM-1 in all members of FCH families

IMT = intima-media thickness of the common carotid; artery,

s-ICAM-1 = soluble intercellular adhesion molecule-1,

$\mathrm{n}=$ number of $\mathrm{FCH}$ families members,

$r=$ Pearson correlation coefficient,

$\mathrm{p}=$ statistical significance level

dent coronary heart disease (CHD) (ref. $\left.{ }^{26-29}\right)$. Another trial has shown that in stable patients with CHD, levels of s-ICAM-1 were associated with increased risk for future CHD events ${ }^{30}$. In contrast, no relationship has been found between s-VCAM-1 and incident CHD in several of these studies $^{26,29,31}$. Levels of s-ICAM-1 - but not of s-VCAM-1 - were also found significantly higher in healthy individuals, in whom subsequent development of symptomatic peripheral arterial disease was documented ${ }^{32}$. In contrast is the finding of Blankenberg et al. who determined in patients with the documented CHD, the level of s-VCAM-1 as the best predictor of mortality due to CHD, after adjustment for other clinical risk factors ${ }^{33}$. Another study proved that levels of s-VCAM-1, in contrast to levels of s-ICAM-1, correlated with severity of clinically manifest atherosclerosis of lower extremity arteries ${ }^{34}$. On the basis of the above-mentioned studies, many researchers consider the levels of s-ICAM-1 as a potential predictor of 
cardiovascular risk in healthy persons, while the levels of s-VCAM-1 may be related to the extent of the existing atherosclerotic involvement and prediction of subsequent cardiovascular progression in subjects with diagnosed $\mathrm{CHD}$ (ref. ${ }^{9,10}$ ). This is supported by our findings. FCH subjects without clinical manifestation of atherosclerosis had elevated levels of s-ICAM-1, but not of s-VCAM-1.

Furthermore, the plasma level of s-ICAM-1 is associated with apoB in hyperlipidemic and with proinsulin in normolipidemic members of $\mathrm{FCH}$ families. The association between lipids and levels of adhesive molecules had been investigated in several studies. Hackman et al. observed elevated levels of s-ICAM-1 in hypercholesterolemic subjects in a relatively small group of patients. Patients with hypertriglyceridemia even exhibited elevated levels of both s-ICAM-1 and s-VCAM-1 (ref. ${ }^{35}$ ). However, larger studies have not confirmed elevated levels of s-ICAM-1 and s-VCAM-1 in hypercholesterolemic subjects $^{36,37}$. Kowalski et al. recorded elevated levels of s-ICAM-1 but not of s-VCAM-1 in persons with hyperlipidemia II b (according to Frederickson) (ref. ${ }^{38}$ ). Kvasnička et al. reported elevated levels of s-ICAM-1 in obese subjects with combined hyperlipidemia ${ }^{39}$. In our group under study, hyperlipidemic individuals showed a significant correlation between s-ICAM-1 and apoB, which corresponds to the findings of other authors confirming an evident and independent correlation between apoB and CHD (ref. ${ }^{22}$ ). Correlation between s-ICAM-1 and proinsulin in normolipidemic relatives indicates an association of s-ICAM-1 with insulin resistance. Marfella et al. found elevated levels of both s-VCAM-1 and s-ICAM-1 in type 2 diabetics and confirmed that acute hyperglycemia increased levels of s-ICAM-1 (but not of s-VCAM-1) in healthy controls too. In contrast, euglycemia normalized elevated levels of s-ICAM-1 but not those of s-VCAM-1 (ref. ${ }^{40}$ ). An association was shown between s-ICAM-1 (not of s-VCAM-1) and insulin resistance in non-diabetic patients and subjects with hypertension ${ }^{41}$. The presence of insulin resistance in $\mathrm{FCH}$ patients is well known and may be related to the concrete lipid profile of individual family members. Vakkilainen et al. showed the more frequent disorder of glucose tolerance in subjects with isolated hypertriglyceridemia or combined hyperlipidemia compared to persons with isolated hypercholesterolemia or healthy controls $^{42}$. Pihlajamaki et al. also reported on a reduced insulin-stimulated uptake of glucose only in subjects with hypertriglyceridemia or combined hyperlipidemia. However, elevated levels of free fatty acids were found in all FCH family members, including those without hyperlipidemia. This finding indicates that even normolipidemic FCH relatives had a certain form of insulin resistance ${ }^{43}$. Increased proinsulin levels, together with higher triglyceride levels and diastolic blood pressure values recorded in our normolipidemic FCH family members could also indicate the presence of insulin resistance. However, with regard to late manifestation of hyperlipidemia in $\mathrm{FCH}$ and the low mean age of this group, it is probable that the NL group also comprises persons in whom $\mathrm{FCH}$ is still latent and insulin resistance is manifested first.
Controversial are results of studies comparing the levels of adhesion molecules and the early morphological markers of atherosclerosis. The Rotterdam study reported on the association between s-ICAM-1 and only carotid plaques, not IMT, nor ankle occlusion index. The levels of s-VCAM-1 did not correlate with any of those parameters ${ }^{44}$. Hwang et al. found a significant correlation between the levels of s-ICAM-1 and IMT but no significant association between IMT and s-VCAM-1 (ref. ${ }^{45}$ ). Rohde et al. showed a statistically significant correlation between IMT and both s-ICAM-1 and s-VCAM-1 (ref. ${ }^{46}$ ) and a similar finding was described by De Caterina et al. ( ref. $^{47}$ ). Our group showed only a correlation between IMT and s-ICAM-1, not s-VCAM-1. This may be explained by the fact that s-VCAM-1 is associated with the extent of existing atherosclerotic involvement and our subjects had no clinically diagnosed manifestation of atherosclerosis.

\section{CONCLUSION}

It is concluded that significantly increased levels of s-ICAM-1 in FCH patients without atherosclerotic manifestation indicate a high cardiovascular risk induced by dyslipidemia, insulin resistance, visceral obesity and arterial hypertension. The levels of s-ICAM-1 may reflect the presence of low grade systemic inflammation and endothelial dysfunction leading to the advancement and progression of atherosclerosis. Correlation between s-ICAM-1 and IMT, respected morphological marker of early atherosclerosis, suggests that assessment of s-ICAM-1 may be useful in prediction of cardiovascular risk for members of $\mathrm{FCH}$ families.

\section{ACKNOWLEDGEMENTS}

Supported by grant VVZ-MŠ 151100005.

\section{REFERENCES}

1. Goldstein JL, Schrott HG, Hazzard WR, Bierman, EL, Motulsky AG. (1973) Hyperlipidemia in coronary heart disease. II. Genetic analysis of lipid levels in 176 families and delineation of a now inherited disorder, combined hyperlipidemia. J Clin Invest 52, 1544-1568.

2. Vaverková H, Weinbergová O, Horčička V, Kubašta M, Vrublovký P. (1986) Familial combined hyperlipidemia. Part II. Clinical picture. Acta Univ Palacki Fac Med 114, 243-259.

3. Venkatesan S, Cullen P, Pacy P, Halliday D, Scott J. (1993) Stable isotopes show a direct relation between VLDL apoB overproduction and serum triglyceride levels and indicate a metabolically and biochemically coherent basis for familial combined hyperlipidemia. Arterioscler Thromb 13, 110-118.

4. Hokanson JE, Austin MA, Zambon A, Brunzell JD. (1993) Plasma triglyceride and LDL heterogeneity in familial combined hyperlipidemia. Arteriocler Thromb 13, 427-434.

5. Hokanson JE, Krauss RM, Albers JJ, Austin MA, Brunzell JD. (1995) LDL physical and chemical properties in familial combined hyperlipidemia. Arterioscler Thromb Vasc Biol 15, 452-459. 
6. de Graaf J, Stalenhoef AF. (1998) Defects of lipoprotein metabolism in familial combined hyperlipidemia. Curr Opin Lipidol 9, 189-196.

7. Keulen ETP, Voors-Pette C, de Bruin TWA. (2001) Familial dyslipidemic hypertension syndrome: Familial combined hyperlipidemia, and the role of abdominal fat mass. Am J Hypertens 14, 357-363.

8. Carlos TM, Harlan JM. (1994) Leukocyte-endothelial adhesion molecules. Blood 84, 2068-2101.

9. Blankenberg S, Barbaux S, Tiret L. (2003) Adhesion molecules and atherosclerosis. Atherosclerosis 170, 191-203.

10. Ballantyne CM, Entman ML. (2002) Soluble adhesion molecules and the search for biomarkers for atherosclerosis. Circulation 106 , 766-767.

11. Salonen R, Salonen JT. (1991) Determinants of carotid intima-media thickness: a population-based ultrasonography study in eastern Finnish men. J Intern Med 229, 225-231.

12. Hutyra M, Slavík L, Novotný D, Karásek D, Halenka M, Vaverková H. (2004) The relationship of selected fibrinolytic markers to early atherosclerosis in dyslipidemic middle-aged subjects. Cor Vasa 46 60-67.

13. Sharrett AR, Patsch W, Sorlie PD, Heiss G, Bond MG, Davis CE. (1994) Associations of lipoprotein cholesterols, apolipoproteins A-I and $\mathrm{B}$, and triglycerides with carotid atherosclerosis and coronary heart disease. The Atherosclerosis Risk in Communities (ARIC) Study. Arterioscler Thromb 14, 1098-1104.

14. Geroulakos G, O’Gorman DJ, Kalodiki E, Sheridan DJ, Nicolaides AN. (1994) The carotid intima-media thickness as a marker of the presence of severe symptomatic coronary artery disease. Eur Heart J $15,781-785$.

15. Visona A, Pesavento R, Lusiani L, Bonanome A, Cernetti C, Rossi M, Maiolino P, Pagnan A. (1996): Intimal medial thickening of common carotid artery as indicator of coronary artery disease. Angiology 47, 61-66.

16. Bots ML, Hoes AW, Koudstaal PJ, Hofman A, Grobbee DE. (1997) Common carotid intima-media thickness and risk of stroke and myocardial infarction: the Rotterdam Study. Circulation 96, 14321437.

17. Bonithon-Kopp C, Touboul PJ, Berr C, Leroux C, Mainard F, Courbon D, Ducimetiere P. (1996) Relation of intima-media thickness to atherosclerotic plaques in carotid arteries. The Vascular Aging (EVA) Study. Arterioscler Thromb Vasc Biol 16, 310-316.

18. Rosfors S, Hallerstam S, Jensen-Urstad K, Zetterling M, Carlstrom C. (1998) Relationship between intima-media thickness in the common carotid artery and atherosclerosis in the carotid bifurcation. Stroke 29, 1378-1382.

19. Bots ML, Hofman A, Grobbee DE. (1994) Common carotid intima-media thickness and lower extremity arterial atherosclerosis. The Rotterdam Study. Arterioscler Thromb 14, 1885-1891.

20. Bots ML, de Jong PT, Hofman A, Grobbee DE. (1997) Left, right, near or far wall common carotid intima-media thickness measurements: associations with cardiovascular disease and lower extremity arterial atherosclerosis. J Clin Epidemiol 50, 801-807.

21. Cifkova R, Skodova Z, Poledne R, Adamkova V, Novozamska E, Jozifova M, Petrzilkova Z, Hauserova G, Duskova A, Hejl Z, Stavek P, Skibova P. (2000) Longitudinal trends of total and HDL-cholesterol in a representative population ample of Czech republic. Vnitr Lek 9, 501-505.

22. Demacker PN, Veerkamp MJ, Bredie SJ, Marcovina SM, de Graaf J, Stalenhoef AF. (2000) Comparison of the measurement of lipids and lipoproteins versus assay of apolipoprotein B for estimation of coronary heart disease risk: a study in familial combined hyperlipidemia. Atherosclerosis 153, 483-490.

23. Veerkamp MJ, de Graaf J, Bredie SJ, Hendriks JC, Demacker PN, Stalenhoef AF. (2002) Diagnosis of familial combined hyperlipidemia based on lipid phenotype expression in 32 families: results of a 5-year follow-up study. Arterioscler Thromb Vasc Biol 22, 274-882.

24. Matthews DR, Hosker JP, Rudenski AS, Naylor BA, Treacher DF, Turner RC. (1985) Homeostasis model assessment: insulin resist- ance and beta-cell function from fasting plasma glucose and insulin concentrations in man. Diabetologia 28, 412-419.

25. Karásek D, Vaverková H, Hutyra M, Halenka M, Novotný D, Budíková M, Slavík L. (2003) Endothelial dysfunction in a families with familial combined hyperlipidemia. Vnitr Lek 49, 623-629.

26. Hwang SJ, Ballantyne CM, Sharrett AR, Smith LC, Davis CE, Gotto AM, Boerwinkle E. (1997) Circulating adhesion molecules VCAM-1, ICAM-1, and E-selectin in carotid atherosclerosis and incident coronary heart disease cases: the Atherosclerosis Risk in Communities (ARIC) study. Circulation 96, 4219-4225.

27. Ridker PM, Hennekens CH, Roitman-Johnson B, Stampfer MJ, Allen J. (1998) Plasma concentration of soluble intercellular adhesion molecule 1 and risks of future myocardial infarction in apparently healthy men. Lancet $351,88-92$.

28. Ridker PM, Hennekens CH, Buring JE, Rifai N. (2000) C-reactive protein and other markers of inflammation in the prediction of cardiovascular disease in women. N Engl J Med 342, 836-843.

29. Malik I, Danesh J, Whincup P, Bhatia V, Papacosta O, Walker M, Lennon L, Thomson A, Haskard D. (2001) Soluble adhesion molecules and prediction of coronary heart disease: a prospective study and meta-analysis. Lancet 358, 971-976.

30. Haim M, Tanne D, Boyko V, Reshef T, Goldbourt U, Leor J, Mekori YA, Behar S. (2002) Soluble intercellular adhesion molecule-1 and long-term risk of acute coronary events in patients with chronic coronary heart disease: data from the Bezafibrate Infarction Prevention (BIP) Study. J Am Coll Cardiol 39, 1133-1138.

31. de Lemos JA, Hennekens CH, Ridker PM. (2000) Plasma concentration of soluble vascular cell adhesion molecule-1 and subsequent cardiovascular risk. J Am Coll Cardiol 36, 423-426.

32. Pradhan AD, Rifai N, Ridker PM. (2002) Soluble intercellular adhesion molecule-1, soluble vascular cell adhesion molecule-1, and the development of symptomatic peripheral arterial disease in men. Circulation 106, 820-825.

33. Blankenberg S, Rupprecht HJ, Bickel C, Peetz D, Hafner G, Tiret L, Meyer J. (2001) Circulating cell adhesion molecules and death in patients with coronary artery disease. Circulation 104, 13361342

34. Peter K, Nawroth P, Conradt C, Nordt T, Weiss T, Boehme M, Wunsch A, Allenberg J, Kubler W, Bode C. (1997) Circulating vascular adhesion molecule - 1 correlates with the extent of human atherosclerosis in contrast to circulating intercellular adhesion molecule - 1, E - selectin, P - selectin, and thrombomodulin. Arterioscler Thromb Vasc Biol 17, 505-512.

35. Hackman A, Abe Y, Insull W, Pownall H, Smith L, Dunn K, Gotto AM, Ballantyne CM. (1996) Levels of soluble adhesion molecules in patient with dyslipidemia. Circulation 93, 1334-1338.

36. Morisaki N, Saito I, Tamura K, Tashiro J, Masuda M, Kanzaki T, Watanabe S, Masuda Y, Saito Y. (1997) New indices of ischemic heart disease and aginig: studies on the serum levels of soluble adhesion molecule-1 (ICAM-1) and soluble vascular cell adhesion molecule-1 (VCAM-1) in patients with hypercholesterolemia and ischemic heart disease. Arteriosclerosis 131, 43-48.

37. Blann AD, Seigneur M, Steiner M, Miller JP, McCollum CN. (1998) Circulating ICAM-1 and VCAM-1 in peripheral artery disease and hypercholesterolaemia: relationship to the location of atherosclerotic disease, smoking, and in the prediction of adverse events. Thromb Haemostas 79, 1080-1085.

38. Kowalski J, Okopien B, Madej A, Makowiecka K, Zielinski M, Kalina Z, Herman ZS. (2001) Levels of sICAM-1, sVCAM-1 and MCP-1 in patients with hyperlipoproteinemia IIa and IIb. Int J Clin Pharmacol Ther 39, 48-52.

39. Kvasnička T, Kvasnička J, Češka R, Grauova B, Vráblík M. (2001) Increasing plasma levels of soluble cell adhesion molecules (sESelectin, sP-Selectin and sICAM-1) in overweight patients with combined hyperlipidemia. Sb Lek 102, 473-477.

40. Marfella R, Esposito K, Giunta R, Coppola G, De Angelis L, Farzati B, Paolisso G, Giugliano D. (2000) Circulating adhesion molecules in humans: role of hyperglycemia and hyperinsulinemia. Circulation 101, 2247-2251.

41. Hak EA, Pols HAP, Stehouwer CD, Meijer J, Kiliaan AJ, Hofman A, Breteler MM, Witteman JC. (2001) Markers of inflammation 
and cellular adhesion molecules in relation to insulin resistance in nondiabetic elderly: the Rotterdam study. J Clin Endocrinol Metab 86, 4398-4405.

42. Vakkilainen J, Porkka KV, Nuotio I, Pajukanta P, Suurinkeroinen L, Ylitalo K, Viikari JS, Ehnholm C, Taskinen MR. (1998) Glucose intolerance in familial combined hyperlipidemia. EUFAM study group. Eur J Clin Invest 28, 24-32.

43. Pihlajamaki J, Karjalainen L, Karhapaa P, Vauhkonen I, Laakso M (2000) Impaired free fatty acid suppression during hyperinsulinemia is a characteristic finding in familial combined hyperlipidemia, but insulin resistance is observed only in hypertriglyceridemic patients. Arteriocler Thromb Vasc Biol 20, 164-170.

44. van der Meer IM, de Maat MP, Bots ML, Breteler MM, Meijer J, Kiliaan AJ, Hofman A, Witteman JC. (2002) Inflammatory mediators and cell adhesion molecules as indicators of severity of atherosclerosis: the Rotterdam Study. Arterioscler Thromb Vasc Biol 22, 838-842.

45. Hwang SJ, Ballantyne CM, Sharrett AR, Smith LC, Davis CE, Gotto AM, Boerwinkle E. (1997) Circulating adhesion molecules VCAM-1, ICAM-1, and E-selectin in carotid atherosclerosis and incident coronary heart disease cases: the Atherosclerosis Risk in Communities (ARIC) study. Circulation 96, 4219-4225.

46. Rohde LE, Lee RT, Rivero J, Jamacochian M, Arroyo LH, Briggs W, Rifai N, Libby P, Creager MA, Ridker PM. (1998) Circulating cell adhesion molecules are correlated with ultrasound-based assessment of carotid atherosclerosis. Arterioscler Thromb Vasc Biol 18, 1765-1770.

47. De Caterina R, Basta G, Lazzerini G, Dell'Omo G, Petrucci R, Morale M, Carmassi F, Pedrinelli R. (1997) Soluble vascular cell adhesion molecule -1 as a biohumoral correlate of atherosclerosis. Arterioscler Thromb Vasc Biol 17, 2646-2654. 